\title{
Contornos de la memoria y textura del olvido en Tierra y tiempo (2015) de Juan José Morosoli
}

\section{Contours of Memory and Texture of the Forgotten in Tierra y tiempo (2015) by Juan José Morosoli}

\begin{abstract}
Resumen
El presente artículo analiza el libro del uruguayo Juan José Morosoli, Tierra y tiempo, identificando elementos de construcción narrativa desde la memoria y el olvido, que apuntalan el aparato ficcional que desde lo rural crea identidad, una que traspasa fronteras. La tierra pasa de ser un sitio a un lugar simbólico donde los territorios están desconfirmados por el poder. La memoria en los personajes del autor minuano está signada por la soledad. Es el campo, como significante, el escenario de conjunción de la tierra que como el olvido, condena y absuelve.
\end{abstract}

Palabras claves

Juan José Morosoli, Memoria, Olvido, Soledad, Campo, Lugar.

\begin{abstract}
This article analyzes the book Tierra y tiempo by Uruguayan Juan José Morosoli, by identifying elements of narrative construction from what is remembered and what is forgotten that lay the supports of the fictional apparatus that uses rurality to create an identity that can surpass frontiers. The land stops being a space to become a symbolic place where territories are unacknowledged by power. The memory in the characters of this author from Minas is marked by loneliness. The countryside, as a signifier, the stage of conjunction of the land, is what condemns and absolves, like what has been forgotten.
\end{abstract}




\section{Introducción}

Juan José Morosoli, (Minas, Uruguay 1899-1957) fue un escritor que comenzó a aprender el oficio a los nueve años en la librería de su tío Cesar Porrini. Esta formación autodidacta se reflejará en las publicaciones de notas y cuentos en periódicos como El departamento, La unión y la revista Minas. Escritor de poesía, teatro, ensayo y artículos, es en el cuento y en el relato breve donde Morosoli se destaca y donde se encuentra su trabajo más rico y fecundo. La obra que se quiere analizar, Tierra y tiempo, consta de veintinueve cuentos y se edita póstumamente en 1959. En 2015 la reedita la editorial colombiana Animal Extinto en un bello y cuidado libro de donde provienen las citas de este artículo.

El mismo Morosoli le aconsejaba al escritor Domingo Pastorino sobre escribir:

El cuento tiene que ser músculo y hueso. Usted que sabe encontrar esto, tire al diablo la carne accesoria. El diálogo lo domina usted, que es decir lo capta usted porque aprecia la justeza con que se expresa la gente del pueblo. Y bien sabe usted que casi todos los cuentistas que andamos por el mundo, usamos la lengua de los otros para decir nosotros lo que se nos antoja, con lo que o desvirtuamos o matamos una cosa tan inseparable de la persona como es el lenguaje -que es decir dentro de esos hombres - y usted mismo siente que ese lenguaje es el que le cuadra, como la cáscara cuadra al fruto. Comprendo que no se puede hacer guiso de liebre sin liebre. Es inútil que la salsa sea mejor que la que gastamos nosotros. Hay que ponerle liebre, que es justamente lo que nosotros tenemos. Ahora no es cuestión de echarla a perder al cocinarla. Y yo por eso hablo así con 
usted, así como no he hablado nunca sobre el asunto, porque yo no me creo autorizado por nada a sentar cátedra, pero me creo obligado con los amigos a decir lo mío. (8)

En Tierra y Tiempo Morosoli define el campo desde el silencio. Chupa la esencia del uruguayo rural como el tuétano de un hueso y lo pone en el plato del papel para que el lector saboree cada historia que deleita por la sabiduría popular. Sus personajes, untados de tierra y barro, maravillan por lo simples. La llanura de sus personalidades deja entrever un sufrimiento y un amor hondo y reconciliador por la vida. El lector masca cada palabra para extraer más de la sustancia y es imposible no pensar en el Llano en llamas de Rulfo, en la precisión de lo breve y en lo soberano de lo mínimo. Sobre todo asalta la sensación de que algo del silencio de las memorias del llano y la pampa, de esa vastedad de ambos, así como de la intimidad de la chacra y la finca, son tan propias como si no hubiera línea divisoria y pudiéramos definir una "identidad Latinoamericana" desde el campo y el "lugar". La idea central de este artículo es determinar la influencia de la memoria y el olvido en Tierra y tiempo y desarrollar la tesis de que desde el campo, la memoria y el olvido reafirman el lugar del gaucho que se aferra al criollismo rural.

Acariciados por la memoria, los dichos de los viejos se actualizan en los jóvenes, por eso en el libro se siente hablar al campo; lo duro y lo compasivo de la soledad. La memoria se traduce mediante metáfora y analogía, se unta de lo cotidiano y lo vuelve maravilloso. En Morosoli la sabiduría es el despojo y la riqueza es no necesitar nada. Hay unos cuentos duros como el acero como Soledad y Destino y otros tiernos y conciliadores como Dos viejos y Flora. No hay punto medio.

La sabiduría en Morosoli es diáfana y simple; la memoria y el olvido se sitúan en el campo como lugar y en el hombre que contempla la tierra y que respira el alba, como Almada el partero que heredó la profesión de su mujer luego de que esta muriera y dice: "Cuando tiene que estar, está. Esto tiene su tiempo como una fruta [...] Creasé que el que está adentro tiene más apuro en salir, que usté en entrar 
a verlo" (77); o el padre que "decía que para hacer una sopa buena hay que no ser nervioso y tutearse con las cosas que se le eche" (132). Bentancor dice de los personajes de Morosoli:

Los personajes -habitantes de un campo sin límites o un suburbio limitador-son vivientes, quizás algo menos que una persona, quizás algo más que un ser humano, caracterizados por un oficio. No es la historia de Juan, de Pedro o de María, es la historia de monteadores, artistas de circo, rezadoras, peones de estancia. La individualidad del personaje no se da por quién es, sino por lo que consigue (o no) hacer. Son vidas humildes que se dejan narrar en algunos de sus días (generalmente igual a ayer, seguramente igual a mañana) para que el cuentista minuano pueda mostrar su silencioso heroísmo con el que superan la trágica miseria que -en forma injusta- sufren. Personajes que el narrador crea con soledad y silencio, como si fueran piezas de un cuadro, estático y monocromático, que el lector tendrá que recorrer, descubrir y entender por la descripción propuesta. (101)

La posición fija de los cuentos de Tierra y tiempo es expositiva, sin embargo, hay una posición variable que es reflexiva del ruralismo criollo. "Morosoli capitaliza su experiencia, su capacidad de observación del otro, del prójimo simple, del ejercitante de un oficio en extinción" (Rocca 12) o cualquier oficio que carezca de trascendencia. Tierra y tiempo exalta el trabajo minúsculo, la experiencia inmediata donde hay "implícita una fuerte preocupación social y aún política en un sentido amplio por esa estructura económica que forma y hasta determina el 'alma' de los de abajo". (Rocca 12)

Pastorino afirma que Morosoli era feliz escribiendo en su casa amplia de Williman 524 inmediata al cuartel de Bomberos, que amaba escribir mientras se envolvía en esa atmósfera cotidiana de trabajo asociada a la tierra (hacer mate, recorrer el jardín, arrimar tierra a las raíces desnutridas, matar parásitos), también 
que se encontraba con gente ruda hasta el absurdo, pero desnuda de hipocresía, proveniente de las chacras, las canteras, los obrajes. Todo esto abunda en su obra; todo eso es su obra. Pablo Rocca lo confirma: "ese Uruguay de generosas conquistas sociales, educativas y sanitarias, de clases medias estables, no se refleja en la obra de Morosoli” (13). En Morosoli esas experiencias personales y cotidianas se vuelven obras de creación y a eso, como propone Latorre, podría llamarse “criollismo, regionalismo, nativismo o vernaculismo". (75)

\section{La tierra y la memoria. El lugar en Morosoli}

La escritura de Morosoli preserva todas las temporalidades del lugar, tal como se fijan en el espacio y la palabra. Desde el marco del lugar, el campo es el indicador del tiempo que pasa y sobrevive. Como lugar, según Augé, el campo perdura como las palabras que lo expresan y lo expresarán aún. El campo en Tierra y tiempo es un lugar por ser un espacio histórico de memoria, de identidad y de relación del hombre con su identidad criolla.

En Tierra y tiempo lo creíble es intangible, el desarraigo de la memoria es ignoto, pero hay afán de recordar o de dejar algún tipo de legado o testimonio. En el primer cuento, El campo, Correa, el patrón, y el negro Sabino, su fiel lacayo, se ensartan en divertidas discusiones de por qué el primero debería tener más terrenos y el segundo lo ve como un sinsentido: "-¿Qué te parece si salgo a comprar a Méndez? -¿Y para qué?” (20).

La ambición va pudriendo por dentro a Correa. El campo lo va consumiendo y, en medio del delirio, el campo le habla: “¿y vos no te vas a pudrir, eh?... ¿y vos de quién sos?... ¿No serás de nadie también?” (21). Y mientras su afán lo desborda, Sabino es el que disfruta. Correa tiene, manda a traer vino y alimentos, mientras el otro es capaz del goce. Sabino no entiende la lógica del patrón. Para él es incomprensible su ansiedad por comprar y comprar campos ya que Correa no tiene familia y no sabe a quién le va a quedar todo. El campo tortura con su mutismo 
a Correa y este siente que habla con él, y el campo le sigue respondiendo: “¿Y quién queda por usted Don Correa? ¿No me sale a recorrer?” (21).

Correa es incapaz de disfrute. La ambivalencia con el objeto de deseo hace de la tierra un objeto pero sobre todo una entidad inasible. El patrón le pregunta al negro Sabino sobre lo que haría en su caso y este le responde lo que el patrón es incapaz de disfrutar. Correa no puede gozar como Sabino por más que lo intente. En El Campo, así como en otros cuentos de Tierra y tiempo, los territorios están desconfirmados por el poder. Los territorios no son de quien quiera poseerlos sino de quien establezca una relación con ellos. El deseo de Correa da pie a un lugar. La tierra pasa de ser un sitio a un espacio simbólico donde es de quien no trata de colonizarla. Algunos personajes como el mismo Negro solicitan permiso de la tierra. La tierra parece todo y el tiempo, estático, no transcurre por la misma fuerza de la cotidianidad que ancla a los personajes en el día a día, donde no se atisba ninguna influencia real del poderoso, del político, de quien detenta el poder, en este caso, de quien cree tener la tierra y no sabe qué hacer con ella. La vida se hace a pesar de la dureza de la vida misma lejos del poder político, pero en sometimiento al poder de la naturaleza. En el caso del Negro Sabino, es el hecho de no tener nada, pero ser capaz de disfrutarlo todo. Pastorino se refiere a "Pepe" Morosoli:

Y luego aquello que estuvo en sus decididos agrados, entra en el olvido por el camino de la indiferencia. Amnesia de superficie, manera de ignorar. Y quien ignora, sepulta. Un hecho, un recuerdo, un amigo. También porque su condición de narrador inmerso en la sociología sin pregonarlo, ha sido múltiplemente analizada por avezados críticos. Queda entonces la persona, el hombre, individuo siempre singular, que usó la literatura como elemento fidedigno de acercamiento a los hombres. (4)

Pastorino menciona la forma de entender la literatura en Morosoli como una extensión de la propia condición humana, que recuerda, desde su propio sentido de individuo, la historia y las historias que va narrando y que escuchaba en el almacén 
y barraca que compró en 1923 y en el cual trabajaría hasta el final de su vida. Un ejemplo de criollismo rural donde el campo (o la tierra) es el escenario mayor del hombre. Aunque el criollismo no sea exclusivamente campesino, “es razonable considerar que en Latinoamérica todavía se vive una existencia elemental y que sus creaciones autóctonas de mayor relieve humano son aún extraídas de la tierra y del paisaje" (Latcham 25).

Es en el campo, como significante, escenario de conjunción de la tierra desde lo simbólico pero también desde lo material, donde la memoria se enraíza dentro de los marcos de simultaneidad y contingencia, y convierte la memoria en el campo, la materialización del lugar. Como nos diría Darío Betancourt Echeverry:

La rememoración personal se sitúa en un cruce de relaciones de solidaridades múltiples en las que estamos conectados. Nada se escapa a la trama sincrónica de la existencia social actual, y es de la combinación de estos diversos elementos que puede emerger lo que llamaremos recuerdos, que uno traduce en lenguaje. (126)

Por más que pasen por el filtro individual, esos recuerdos se hacen también colectivos en el lenguaje morosoliano: un lenguaje que parece común a todos los cuentos y a todas las historias, un lenguaje simultaneo que habla del allá pero también del acá; de uno y también de todos. El lugar en Morosoli se cumple por la palabra, se configura en el intercambio de las palabras simples y las conversaciones austeras, que para Augé, se da en la connivencia y la intimidad cómplice de los hablantes.

El campo despoblado es fértil por su vacío. "No puede extrañar, entonces, que la soledad y la 'callada' muerte sean las variables más reiteradas en sus cuentos" (Rocca 13). La tierra se sitúa desde la parquedad pero los cuentos "aluden a una genérica condición humana y no solo a una circunstancia provinciana" (Rocca 13). Dentro de la narrativa morosoliana esta soledad humana se destaca en Tierra y tiempo. Esa soledad atraviesa la tierra y se apropia del tiempo mismo, y los 
personajes solo atinan a tratar de lidiar con ella de la mejor manera que pueden suplantando su egolatría con resignación. "Ese es el espacio y esa es la gente del narrador. Allí donde el pueblo se hace campo es el lugar natural de los seres que viven en las páginas del minuano" (Bentancor 102). Por ejemplo, en el cuento Un huérfano: "El cigarro le achicó la pieza, venció la soledad que la finada había amontonado en su vida y le trajo aquel algo que él necesitaba para no estar solo, abrumado por las cosas. Entonces preparó el mate. Y estuvo horas dele mate y cigarro. Cigarro y mate". (105)

En El Campo la tierra parece narrar a los personajes y no lo contrario, por eso la tierra es la que tiene la memoria, y el dolor se marca con la distinción de las horas que no hacen mella en los días. No por narrarlos sino por reflejarlos como sujetos, la tierra los confirma como en el caso de Sabino o los anula como con Correa. Acá nadie puede poseer la tierra realmente y el papel del título de propiedad resulta meramente anecdótico.

El criollismo morosoliano, como modalidad literaria, se manifiesta en el repudio de los personajes por las "influencias externas que amenazan con ahogar los caracteres y costumbres tradicionales de un pueblo" (Montenegro 56):

La crítica morosoliana al colonialismo cultural mediante la búsqueda de una expresión que evoque al "gran personaje cósmico" y al "proletariado rural y trashumante" guarda así una bienvenida familiaridad con los narradores transculturados que el crítico Ángel Rama identificaba como aquellos sujetos capaces de reestructurar la lengua literaria de un modo radical, superando la mera traducción y apropiación de artificios verbales provenientes de la cultura dominante. (Aguiar 186)

Con Morosoli, el lector no siente el paso de los días por más que el narrador diga que el personaje maduró o murió. El tiempo trascurre por trashumancia y vuelve la memoria un constante movimiento. El protagonista del cuento Un gaucho dice: "Mi pago es donde yo ando" (63). Hombre y animal se desplazan de acuerdo 
con las urgencias del clima y la tierra, por eso el desarraigo a un lugar específico es permanente y la tierra ancha, que arropa y mimetiza, es la constante. El hogar, la vida, es donde el sujeto va estando: en la inmensidad de la pampa. La huella se borra y la palabra es el único testimonio de que alguien ha transitado el campo. "Sin que dejen de comunicar rasgos de la naturaleza humana total, estas criaturas hablan desde una precisa geografía y enseñan las variaciones psicológicas de personajes populares ubicados en un lugar del mapa" (Rocca 14); un lugar que puede estar ubicado en cualquier parte de Latinoamérica. Por eso en Morosoli la tierra que se diagrama local se torna universal.

Una de las cosas recurrentes en el libro, que se puede rastrear con facilidad, es el tema del despojo económico que da la muerte, la ignominia y lo ridículo de querer tener la tierra. En Flora el despojo hermana la muerte con la dignidad y con la sabiduría de ese olvido-recuerdo de los muertos. Según Bentancor, en Morosoli “nada es trivial, todo es básico. Básico por lo primitivo y por lo necesario" (102).

En los años treinta los uruguayos "se enfrentan al avance de nuevas realidades que terminarían por clausurar el universo de personajes, costumbres y tradiciones, según lo confirman los crecientes índices de despoblamiento rural y la concentración de la propiedad de la tierra" (Rocca 15). Morosoli ya anticipa el afán de progreso que implica el dominio y la concentración de la propiedad. Tierra y tiempo no utiliza el recurso facilista de presentar al ser como sumatoria del territorio. No solo reflexiona sobre la explotación en todas sus manifestaciones (agrarias y humanas), sino también sobre la imposibilidad y el conflicto de la titulación de la tierra, sobre la colonización del espacio por encima del bien y sobre el aprovechamiento del recurso. La tierra va más allá del "silencio dorado manchado de verde bajo los árboles que dejaba entrar el aserrín de hierro de las cigarras" (44). La tierra es el espacio simbólico y político de conflicto donde se batallan y se dirimen los vacíos del alma humana donde se arraigan la emoción y la identidad. "En la narrativa, la noción de vanguardia política puede reinterpretarse como una apuesta literaria, angustiosa y urgente, que examina la vida rural en pleno triunfo de la modernización" (Rocca 16). 
Según Veloso, esta noción de la propiedad de la tierra desvinculada de la necesidad y del uso está ligada a la noción de la acumulación, del improductivo tener por tener; es el estructurador del discurso en la región de la Pampa, marcos fundantes de los grandes latifundios que aún dominan las zonas rurales en América Latina (75).

Pero el afán de acumulo de la modernización envenena el alma de Correa hasta la locura; la tierra va consumiendo desde adentro al patrón:

-¡Patrón! ¡Vaya pa' dentro, patrón! (...)

A Sabino le pareció que tenía los ojos de vidrio helado con reflejos que saltaban para todos lados como si estuvieran rotos por dentro. (23)

En El campo, Correa dice que "tener plata es como tener enemigos o remordimientos" (18). "En esta encrucijada, Morosoli resuelve la mayor de sus paradojas: mostrar que el capitalismo desvirtúa las relaciones entre la gente" (Rocca $18)$.

En Un bicho se expone también esta relación ambivalente con la tierra, la libertad que implica, pero sobre todo el tema de la posesión. La voluntad del joven montaraz y precoz Martín choca con la férrea personalidad de su tío. El joven asume la alteridad del otro y no halla problema en regalar todo al que lo necesita; el tío riñe con él para preservar la integridad de su negocio, la posesión del capital. Al final Martín retorna a su vida anterior: "más vale ser sobrino de un chancho que de un tío -contestó. Y siguió rumbo al monte donde no había rejas, ni negros, ni tíos. A vivir a lo bicho otra vez" (41). Los personajes morosolianos buscan permanentemente su lugar en el mundo: "El pez agua, el pájaro cielo, el vagabundo camino..." (99). La libertad que da no el pedazo sino la totalidad de la autonomía en la tierra.

En La Cuña, el abuelo está en desacuerdo con el matrimonio de su nieta con Rondán. Algo de su carácter no cuadra: "si hay un ñudo, no desata. Corta" (97). Rondán es la cuña que quiebra el tronco de las costumbres y de la historia familiar 
como "el arado del cuñado que anda y desanda abriendo la tierra" (99); es el hombre que se domestica en la familia, pero que sueña con la libertad del campo "de aquellos olores, aquellos ruidos y aquella escena" (101). Para Montenegro, "este criollismo literario supone que en nuestra manera de ser y en las creencias heredadas de nuestros mayores, hay virtudes inherentes y exclusivas que poseen un mérito superior, una belleza y encantos únicos" (62).

Para Byung-Chul Han, "la memoria no es un órgano de mera reposición con el que podamos hacer presente lo pasado. En la memoria lo pasado cambia de continuo. Es un proceso progresivo, vivo, narrativo" (28). La memoria en Morosoli, desde el movimiento, proclama la tierra como espacio de unión íntima de los sujetos con su pasado y de lo emancipatorio que pudiera haber en él. Esto desempeña una función importante en el relato, por eso la tierra se despolitiza y vence la codicia. La memoria se hace más fuerte conforme los horizontes del campo se expanden, porque la tierra revela el alma, no la propiedad.

En Canteros se ve precisamente esto último en los tres explotadores de piedra caliza: Rosi, Arboleya y Fagina. La tierra acá es proveedora, la tierra es madre; esa tierra es el "cerrito". Se supone que Rosi es el dueño, pero realmente esta pertenece a quien la trabaja. Ninguno de los tres es empleado de nadie. Venden el producto de su trabajo a la Sociedad Anónima que quiso comprar su pedazo de cerrito: "Me hago de plata pero quedo bajo patrón... Más, un patrón al que usted no le ve la cara... Las anónimas, mire, tienen eso: usted los sufre pero no los ve... Son como las enfermedades..." (132). El éxito de los tres es la libertad de no saberse poseedores de la tierra. Viven al corte del día, gastan lo que tienen, disfrutan y vuelven a vivir de la tierra, no de trabajarla.

Se podría decir que los espacios morosolianos, en gran medida ficticios, son esencialmente universos de reconocimiento. El campo como universo de reconocimiento es, como dice Augé, propio de los universos simbólicos que constituyen para los "hombres que los han recibido como herencia, un medio de reconocimiento más que de conocimiento: universo cerrado donde todo constituye signo, conjuntos de códigos que algunos saben utilizar y cuya clave poseen, pero 
cuya existencia todos admiten, totalidades parcialmente ficticias pero efectivas" (39).

Estos tres hombres son la perfecta representación del gaucho, ese "que se identifica con la libertad, el coraje y la aventura es también aquel que honra la palabra dicha, responde por sus actos y firma compromisos" (Veloso 76). Sin embargo, para Bentancor, y cabe la aclaración, "el gaucho del que Morosoli hablará en algunos de sus cuentos (...) es un recuerdo, una añoranza. Nada más que eso. En realidad, el foco morosoliano es el siete-oficios, aquel descendiente del gaucho que pasó por el periodo de peón de estancia para terminar, (...) encorralado en los suburbios de las ciudades" (102). Esa añoranza del gaucho en Morosoli define varias características fundamentales de la identidad criolla: "valentía, vitalidad, coraje, ingenio, audacia, fatalismo" (Vega 101).

Pastorino manifiesta que la fuerza y la originalidad expresivas de la narrativa morosoliana radican en poder captar y trasmitir esos estados de alma de su gente siempre con estricto sentido de respeto al lector. Por eso, su literatura no pierde vigencia:

Y a Juan José Morosoli pueden olvidarlo los que nunca le leyeron; o prejuzgando le leyeron, aburridos por anticipado, con indiferencia; o los que no tuvieron el corazón templado y abierto para acoger su hermoso y fraterno mensaje solidario. Lo suyo, por genuino y auténtico, se mantendrá con absoluta salud, sin solución de tiempo (11).

Los contenidos de la memoria dependen de situaciones sociales históricas a las que hay que agregar un contenido emocional (Basaure 115). Morosoli privilegia lo emocional por sobre lo histórico, como la señora Flora en el cuento del mismo nombre, en que visita a los muertos para que los vivos se sientan bien. A ella le encargan el cuidado de los panteones. El recuerdo opera en lo fundamental de la culpa. "Le contestaban que no podían visitar las tumbas pero le enviaban dinero para flores. -Los vivos se sienten tranquilos cuando gastan un peso con los muertos" (189). 
En Flora las personas son lo que son después de muertas; el capital no vale nada. Cuando el hombre no tiene nada, finalmente es.

En el cuento Dos viejos el tiempo es el protagonista y la espera que exaspera al inicio se hace cotidiana y da sentido a la realidad. Por eso el tiempo pasa. Uno de los viejos quiere que pase, pero el tiempo se rehúsa. Un evento sucede a otro pero esa espera se ancla en la tragedia de existir sin un motivo diferente al de la espera misma. Los dos viejos concilian sus propias soledades y la espera cambia de sentido. El tiempo y la memoria, ahora compartidos, se invisten de la cotidianidad de los días. Sin embargo, el viejo Llanes aflora su memoria reprimida cuando confiesa que mató a un hombre y cuando llega un supuesto hijo. Esa memoria también es sinónimo de responsabilidad, una de la que Llanes carece: “y los hijos solo son de la madre, no del padre..." (177). Ese escape y esa sensación de bienestar del olvido se abordarán en el siguiente apartado.

Desde la Memoria plástica que plantea Barrientos con base en los postulados de la filósofa francesa Catherine Malabou sobre el concepto de plasticidad se puede hacer un análisis de Tierra y tiempo. La memoria plástica se define como la

reapropiación de la palabra negada, un movimiento irrefrenable que atraviesa las rutas ficcionadas de los horizontes sociales e íntimos en un intento por valorar nuevas formas de decir y pensar aquello que ocurre más allá de los límites de los grandes faroles de la historia (66).

Los relatos de Tierra y tiempo tienen la extensión y la hondura precisas. Morosoli no gasta ni hace grandes artificios para desarrollarlos. Cuando se comienza uno, se anticipa la brevedad del tiempo en el que va a terminar, mas no se sabe cómo va a hacerlo. Los personajes "son pintados en un momento de su vida -que puede ser cualquiera- en el que pasado y futuro se funden en un presente indescifrable. La casi descripción de ese momento único y casi estático será la base narrativa de los cuentos" (Bentancor 101). 
La textura del tiempo, vuelto memoria, se torna caricia en esas rutas ficcionadas que encuentran nuevas formas de decir y pensar lo dicho sobre la tierra, su dominio y los vericuetos de la memoria en ese Uruguay rural de Morosoli.

\section{El olvido en la tierra y el tiempo}

En Dos viejos el relato se debate permanentemente entre cierres y aperturas; la apertura de una naciente amistad y el cierre del propio pasado de los protagonistas. El pasado se clausura desde el silencio y la represión del recuerdo. La memoria acá cobra especial significado por las capas que la contienen. El lector penetra esas capas poco a poco. Los viejos se acompañan con el silencio más que con las palabras que tratan de contener todo y al final no dicen nada. Su amistad inicia en la ventanilla de pagos de la oficina de jubilados. Son solidarios el uno con el otro, mas no son condescendientes con sus dificultades. La consciencia de finitud, saber que todo termina, dota de sentido sus acciones, así sea temporalmente. Lo fatal acá no es la muerte sino el afrontamiento de que lo único certero para ellos es el olvido. Es claro que la memoria también es un hecho temporal y, desde la lectura, podemos abrazar la finitud de los viejos no como tragedia sino como posibilidad. Para Barrientos, "una memoria plástica es siempre un ejercicio de escritura desgarrada y expuesta, que no tiene miedo de poner en el espacio de lo público aquellas cosas que supuestamente debieran sólo quedar relegadas a los rincones oscuros de los mundos privados" (66).

Los viejos a veces se ocultan como pueden entre la indignidad, el deseo y la culpa. Otras veces abrazan la melancolía, la duda y la nostalgia y no las sienten extrañas. "El viejito calló. Se concentró. ¡Qué hombre este Llanes! Sembró hijos. Mató un hombre. Olvidó a los vivos y a los muertos. Está solo y es feliz" (177). No pueden luchar contra la naturaleza inevitable del olvido y lo que hacen es aprovecharla para alcanzar el fin superior de su bienestar. Ese olvido también se 
camufla en el plano transcurrir de los días: un eterno presente despiadadamente abúlico como esta conversación:

-Sí. Eso sí. Pero yo me acuesto y demoró en dormirme... Y después que me duermo me despierto otra vez... Me cuesta volver a dormirme... hasta que me levanto temprano a esperar.

-¿A esperar qué?

${ }_{-}$¡Nada! ¿Usted sabe lo que es esperar nada?

-Si le digo que no entiendo.

-Espero la hora de almorzar... Salgo y entro y salgo otra vez... Doy vuelta la manzana y vuelvo... Me siento aquí y espero. Calculo que son las doce y son las diez... Las doce demoran mucho en venir... Almuerzo y tengo que esperar que pase la tarde y la tarde no se va nunca. Cuando llega la noche espero la cena... me acuesto... No me duermo y lo peor es que me tengo que quedar quieto porque tengo miedo de despertar a los otros...

Escribe Clarice Lispector que "los hechos son sonoros pero entre los hechos hay un susurro" (34). Ese susurro es la subjetividad y se encuentra entre los diálogos y los silencios de Tierra y tiempo; ese susurro es la personalidad del olvido, es lo dispar de la memoria.

Rieff acierta cuando habla de la imposibilidad de que todo perdure de forma reconocible para los que aún están vivos y por toda la duración de la humanidad; el olvido no es solo el proceso dicotómico que es a su vez caprichoso y necesario (el olvido que salvaguarda y protege), sino que es también la memoria que imprime un sentido. Los recuerdos del pasado son tan brumosos como apasionados. La memoria no es solo un proceso solitario e ingente. Aunque brumosa, aporta sentido y dirección. La memoria morosoliana no es solo un proceso ontogenético. Esa memoria filogenética, ese registro humano además de ser histórico es evolutivo y no solo hablan los personajes de aquello que recuerdan y de aquello que quieren 
olvidar, también habla la historia uruguaya rural a través de la tierra. Como afirma Rieff, "para no perder el juicio solo podemos vincularnos con el tiempo en el cual estamos destinados a vivir y morir y con los periodos relativamente breves del pasado y el futuro con los que podemos sentirnos afines" (25). En el tiempo sincrónico, ese tiempo que corresponde a un periodo particular, el olvido protege, pero Morosoli alarga esa brevedad más allá de los caprichos y de la imperfección de la memoria y esta duele, como el olvido. El lector puede elucubrar, así sea desde la imaginación, un pasado más allá de los hechos y un futuro más lejano que las posibilidades. La memoria tiene un límite y una fecha de caducidad, pero en la literatura de Morosoli ese límite se prolonga decenios quizá, mucho más de lo que podrían lograr la memoria y el relato oral por sí mismos, para recrear o proyectar la imagen del uruguayo rural a través de la narración y del silencio. "Las naciones siempre eligen su mito -codificado en el recuerdo-por encima de la historia" (Rieff 32). Como acto de resistencia las memorias históricas se contraponen a ese mito, porque los que las hacen son los de abajo:

Esta posibilidad de ser sin necesidad de estar es una conquista que, como dijimos, democratiza la cultura en el país; pero que, más allá de eso, abre las tranqueras y los portones para que también aquellos que son de la periferia, con sus características, sus especificidades y sus tradiciones, puedan arribar al centro y ocupar un lugar nuclear en la producción cultural de la nación. (Bentancor 108)

El olvido en Dos viejos es anacrónico. "Eso no es nada. Yo le digo porque sé... Feo es dormir con un muerto abajo la almohada... Si usted mata pa defenderse el muerto se va... Si no, se queda... la justicia es usted ¿no le parece?” (176). En Tierra y tiempo el perdón se asocia al olvido. Hay varios rencores vivos por ahí. La moral, al igual que la justicia, es la propia medida del hombre: inicio y fin. Es difícil perdonar porque se confunde con aceptar, porque el perdón validaría la conducta que ofende; por ello existe la creencia de que al perdonar se le dice al otro que lo 
que hizo estuvo bien. La ira es potente, el miedo protege, por eso el perdón no se fuerza ni se reviste de olvido. El perdón, un acto de dignidad humana, es acá un acto de reconciliación de Llanes pero consigo mismo. La culpa se subsana con olvido, con la compasión de la memoria se dejan de acariciar la rabia y el deseo de venganza: "Tuve preso y después salí... Y si le digo que no me acuerdo de la cara y del nombre del muerto, no le miento..." (176). Por eso es fácil reprimir el recuerdo y difícil hacer memoria y reconocer las cargas del pasado, porque la memoria no brota como una emoción, sino que se construye y madura como un pensamiento, quizá como un ser. En Dos viejos el perdón es venganza y el olvido conciliación:

En la mitología griega, Lethe, la diosa del olvido, se opone a Mnemosyne, la diosa de la memoria y madre de las musas. Empero, los papeles de las dos diosas no son tan unívocos como puede parecer al principio. Cada uno de nosotros sabe que la memoria puede convertirse en obsesión (...) En sus reflexiones sobre la utilidad y detrimento de la historia para la vida, Friedrich Nietzsche enfatiza los peligros de una memoria excesiva al escribir que "hay un grado de insomnio, de rumia, de sentido histórico que daña a lo vivo y que hace que, al final, sucumba, ya sea un hombre, un pueblo o una cultura"; o, expresando la misma idea a la inversa, que "lo no histórico y lo histórico son igualmente necesarios para la salud de un individuo, de un pueblo y de una cultura.” (Kohut 18)

El pasado de Llanes es la llama, el fuego que borra; la memoria es el humo que queda una vez se ha extinguido el fuego. Algunos leños crepitan, otros se consumen sin dejar rastro. A veces el humo se ve a kilómetros de distancia. Este no es el caso. Se suprime el recuerdo, no hay memoria porque se anula, no hay melancolía ni mucho menos arrepentimiento. Llanes se da al olvido, lo abraza y eso lo hace vivir. "Bueno...Si las cosas no entraran y salieran de uno... ¡Dios nos libre!..." (176) 
La tierra ancla en el presente y tiene el poder de reconciliar, pero en otros cuentos como Destino, la tierra y la memoria hacen mella en los cuerpos y a veces no se acepta con el mismo estoicismo ese dolor hondo. Las emociones y los sentimientos de los personajes no son fáciles, no brotan con naturalidad. Cuando se permiten son contenidos y duros, ásperos y secos como la llanura misma. Los pocos que se permiten el llanto, como el hombre que vende el burro, su único amigo, al circo para alimento de leones, lo hacen con rabia medida. No es un llanto fácil; lo hacen como negociando con su propio dolor los intereses para permitir que aflore en cuotas bajas. Es entonces cuando el olvido se asienta tanto en la tierra como en el tiempo.

Para Marcuse, "el recuerdo es una forma de disociación de los hechos dados, un modo de mediación que rompe, durante breves momentos, el poder omnipresente de los hechos dados" (129). El olvido acá tiene una doble vertiente: una curativa y otra totalizante; la primera alivia el dolor y dota de esperanza, la segunda somete el espíritu, soslaya la responsabilidad de los hombres y los encadena a las lógicas de un pasado, latente, y a un futuro desconocido y terrorífico. La memoria recuerda el terror y la esperanza que han pasado los hombres de Morosoli:

pero mientras en la realidad el primero regresa bajo formas siempre nuevas, la última permanece como una esperanza. $\mathrm{Y}$ en los sucesos personales que reaparecen en la memoria individual, los temores y las aspiraciones de la humanidad se afirman a sí mismos: lo universal en lo particular. (129)

Los personajes de Morosoli poco conocen su pasado y las formas de poder y gobierno, por eso su dolor se alivia con esperanza y olvido de haber sido abandonados, de la soledad, de las muertes, del desarraigo, como Montes el gaucho que no se ancla a nada. $\mathrm{Y}$ aunque el relato mismo les permite descargar sus propios 
resentimientos y dolores, la soledad coquetea permanentemente y hace que olviden y que sean olvidados.

Para Veloso la noción de atemporalidad de Morosoli, silenciada en la superficie del discurso, está contextualizada en el interior, por ejemplo en el enunciado de Montes: "mi pago es donde yo ando" (63), o en Destino, y solo en este interior, "puede ser oída y permitir que se exteriorice el sentido de simultaneidad temporal entre el pasado, el presente y el futuro contenido" (Veloso 76).

En Destino Olmedo encuentra su pasado. Se hace referencia a unos tales Almadas: Pedro y María. María era su padre. Ambos mueren ahorcados. El destino había encontrado a Olmedo. "Porque uno anda sin que el destino se acuerde de uno, hasta que un día lo encuentra, se acuerda de uno y..." (59).

Olmedo se dirige a la posada de El francés en busca de respuestas con el pretexto del trabajo. Traban amistad, pero la bruma del olvido se va disipando en Olmedo: "Una conversación llena de silencios y estrellas les endulzaba las horas. El francés iba sacando de adentro su alma de padre frustrado y a Olmedo le empezaba a nacer como una como niñez que nunca había conocido" (60).

Destino tiene un punto de reconciliación con ese pasado. El silencio de Olmedo hacia su amigo el Negro sobre su experiencia con ese pasado es la tapadera de la niñez traumática y perdida que pretende enterrarse del todo. El olvido acá tiene una lógica circular, aunque el olvido reprimido es falso y mortificante. El cuento jamás desentraña el pasado de Olmedo que ahora deambula como una sombra que otra más grande va consumiendo. Se intuyen las fracciones de un niño arrebatado de su propia niñez y una no-relación significante con esos hombres referidos que se colgaron y que ahora hacen mella en su presente. Olmedo al final también se cuelga como lo habían hecho los Almadas. El campo es triste, lo ve así la noche anterior al suicidio. El destino había finalmente cumplido la cita con Olmedo.

El elogio del olvido en Dos viejos es ahora la condena de la memoria, la difuminación del olvido y la materialización del sino trágico en Destinos, pero en 
Tierra y tiempo el olvido también es paradójico y hasta burlesco, y roza lo cruel como en el cuento La negra donde Morosoli expone la esclavitud, la ingratitud y la lucha de clases: "La señorita hizo testamento. Le deja todos los bienes a la iglesia. Usted tiene que abandonar la casa" (152). María Celeste había sido criada junto con la señorita menor de la casa, la niña Ángela:

Fue entonces que Alcira anunció que María Celeste sería de la niña Ángela. Aquel regalo resucitaba la abolida costumbre de la colonia cuando los esclavos se podían dar, regalar y vender y los esclavitos negros eran los juguetes vivos de los niños hasta que dejaban de ser niños. (150)

María Celeste cuidó a Ángela hasta sus últimos días y de vez en cuanto veía a su propia madre biológica, Alcira. María Celeste es anulada por completo y en ella no se asoma ninguna gratitud cuando Ángela muere. El tiempo que pasaron juntas no significó nada para desgracia de La negra, lo cual le recuerda que los de abajo siempre tendrán que quedarse abajo. María Celeste al final vuelve con Alcira y con el resto de sus hijos que jamás fueron sus hermanos: extraños unidos por la sangre. Ese olvido y esa anulación, a la vez recordatorio, sitúan a María Celeste en un espacio, en un lugar desterritorializado de su historia como mujer, pero que le recuerda el lugar histórico de identidad al cual nunca dejó de pertenecer. "No podrían imputar a la nostalgia o a las fantasías de la memoria los cambios de los que da testimonio objetivamente el espacio en el cual continúan viviendo y que no es más el espacio en el que vivían" (Augé 61). Por más que quisiera, nunca dejó de ser La negra, nunca dejó de habitar ese lugar.

Algunos de los personajes parecen caer siempre en las mismas lógicas perversas y cotidianas, como en el cuento El casero cuando Álvarez, uno de los inquilinos, tras la muerte del cruel y estricto casero Don Elías se pasa a vivir a su cuarto y sentencia: "Me pasé para cuidarla, no porque el hombre se haya ido vamos a abandonar los intereses [...] pero estén tranquilos que las cosas van a seguir igual" (169). En este cuento se instaura un olvido transitorio en los inquilinos, pero ese 
mismo olvido del arrendatario anterior instaura uno nuevo, un orden que perpetúa el sometimiento para que la dinámica permanezca igual.

\section{Conclusiones}

En Tierra y tiempo los contornos de la memoria se ligan a la condición humana del hombre uruguayo del campo, pero esa memoria azarosa que da testimonio de una vida muy particular del sujeto que podemos considerar postgaucho se puede extrapolar a una condición del pensar latinoamericano, que es rural, íntimo y a su vez generalizante y permite la identificación en otras latitudes de nuestra geografía. "Y es precisamente en esa intersección, en ese eje de abscisas entre lo individual y lo colectivo, entre lo privado y lo público, donde opera la literatura como práctica memorialística" (Vilavedra 3).

Morosoli busca "llevar a cabo una escritura documental cuyo apoyo en la representación etnográfica logra apropiarse del Otro desde una perspectiva que respeta e intenta entender su singularidad desde adentro" (Tani, citado en Aguiar 186). Esa disección del sentir a través de la memoria y de la relación con la tierra, y no solo desde la evocación y lo constatable, es un análisis del anhelo de posesión que pasa por la búsqueda del sujeto de su lugar en el mundo; el reconocimiento más allá de las fronteras que valida la identidad a través de la colonización de la tierra. Valencia nos dice:

Experimentar la memoria a partir de la tradición oral, del relato que cobra vida en el recuerdo, en la evocación, en la tensión entre el pasado y el presente, hace que cada ser partícipe de este proceso experimente emociones, conmociones y sentimientos que lo confronten con su propia humanidad y la del otro, con su realidad y la de los demás. (180) 
La axiología morosoliana parte de la complejidad de la construcción narrativa del cuento y desemboca en el punto de vista del sujeto del común, cuya narrativa es capaz de movilizar la consciencia de clases, la desigualdad, la marginalidad y el pasado concebido como ajeno, doloroso o negado. Ese es el enclave en la textura del olvido: una doble vertiente, totalizante o curativa, que culpa a la vez que exculpa. El olvido en Morosoli es músculo y hueso y, junto con el silencio, es sustancia vital que recorre lo contado y lo callado. El olvido introduce el elemento de ruptura a la problematización del pasado que en muchos casos es signado por la violencia, la tragedia, pero sobre todo, por la simpleza de la cotidianidad. Tanto memoria como olvido en Tierra y tiempo homenajean lo simple y lo diario. Los acontecimientos se tejen desde lo minúsculo y revisten la lectura de una intimidad sobrecogedora que refleja el alma de los personajes y se identifica con ella. Lo periférico de la marginalidad transita por las polaridades del olvido que protege y condena y por la memoria que testimonia y confirma. Para Aguiar las operaciones críticas realizadas por Morosoli "permiten ahondar en la condición del ser latinoamericano mediante la reconstrucción del pasado, ahora devuelto al presente en forma de productos "originales" que de esa manera reinscriben la tradición local” (186).

Los sistemas de memoria social, individual y colectiva en Morosoli son sistemas de acción complejos capaces de producir diferentes niveles de significado y producción discursiva. Según Aguiar en el universo morosoliano hay un tránsito dialógico entre el solipsismo del escritor letrado y una representación literaria de subjetividades y caracteres orales que pueblan el campo y la tierra y la convierten en lugar; un lugar donde el criollismo rural prolifera y se valida. Pretender amalgamar esos múltiples discursos subjetivos en Morosoli, por más que se parezcan, mutila el significado y corta las líneas del tejido relacional que pueden facilitar el acto de recordar y olvidar en los personajes. En ellos el olvido a veces es necesario, pero el hacer memoria, que es voluntario y no mecánico, es una obligación para reconciliarse con su propio pasado o para encontrarse con el destino. Morosoli rescata el ideal del gaucho y el criollismo desde la dignificación 
de lo rural y se ubica en un regionalismo literario que recoge y preserva en la memoria las tradiciones que convierten el campo y la tierra en lugar.

El lector es testigo de la mecánica del artefacto simple pero contundente que construye Morosoli con engranajes minúsculos como la delicada ironía, ese "paisaje rural que se acerca al campo más allá del espacio" (Bentancor 107), y la tierra que trasciende el paisaje y hace que el campo se vuelva simbólico, reapropiándose de la palabra a través de rutas ficcionadas que parecen muy reales, como propone la memoria plástica.

\section{Bibliografía}

Aguiar, Gonzalo. "Tradición y Reinvención en la Historia Intelectual Uruguaya" Revista de Estudios Hispánicos, vol 51, 2017. https://www.academia.edu/35544125/Tradicion_y_reinvencion_en_la_hi storia_intelectual_uruguaya

Augé, Marc. Los no lugares. Espacios del anonimato. Una antropología de la sobremodernidad. España: Gedisa. 2000.

Barrientos, Panchiba. "Audre Lorde, una memoria plástica para estallar la diferencia" Revista Nomadias, vol. 23, 2017. https://nomadias.uchile.cl/index.php/NO/article/view/47336

Basaure, Mauro. "Hacia una reconstrucción de los conflictos de la memoria. El caso del Museo de la Memoria y los Derechos Humanos en Chile". Revista MAD, vol. 37, 2017. https://revistamad.uchile.cl/index.php/RMAD/article/download/47278/49 320

Bentancor, Milton Hernan. "Juan José Morosoli: La periferia llega al centro" Revista Literatura em Debate, vol. 9, 17, 2015. http://www.revistas.fw.uri.br/index.php/literaturaemdebate/article/view/1 844

Betancourt Echeverry, Darío. "Memoria individual, memoria colectiva y memoria histórica: lo secreto y lo escondido en la narración y el recuerdo" UPN, Universidad Pedagógica Nacional. 2004. http://bibliotecavirtual.clacso.org.ar/Colombia/desupn/20121130052459/memoria.pdf 
Han, Byung-Chul. La agonía del eros. Barcelona: Herder. 2014.

Kohut Karl. "Literatura y memoria" América: Cahiers du CRICCAL, vol.30, 2003. Mémoire et culture en Amérique latine. https://doi.org/10.3406/ameri.2003.1598

Latcham, Ricardo; Montenegro, Ernesto \& Vega, Manuel. El criollismo. Chile: Editorial Universitaria S.A. 1956.

Latorre, Mariano. Autobiografía de una vocación. Algunas preguntas que no me han hecho sobre criollismo. Chile: Editorial de los anales de la Universidad de Chile. S.F.

Lispector, Clarice. La hora de la estrella. Buenos Aires: Corregidor. 2015. Marcuse, Herbert. El hombre unidimensional. Barcelona: Planeta de Agostini. 1993.

Morosoli, Juan José. Tierra y Tiempo. Colombia: Editorial Animal Extinto. 2015. Pastorino, Domingo. Rocca, Pablo. Felipe, Adriana. Raviolo, Ever. "Cuatro Ensayos sobre Juan José Morosoli”. Fundación Vivian Trias, vol. 6, 1999. http://www.fundacionviviantrias.org/sites/default/files/Cuaderno06.pdf

Rieff, David. Contra la memoria. Colombia: Debate. 2011.

Valencia, Angélica María. “Tras bambalinas. Un momento para la reflexión. Importancia de la recuperación de la memoria histórica y las masacres en Colombia a través del teatro" Educación y ciudad, vol. 31, 2016, pp. 175-184.

Veloso, Maria Thereza. "Montes, de Morosoli: sujeito e discurso no semfronteiras de si mesmo". Signo. SantaCruzdo Sul, vol. 40, 69, 2015. https://online.unisc.br/seer/index.php/signo/article/view/6698

Vilavedra, Dolores. "Literatura en el espacio público. Rivas y su obra: un punto de Inflexión en la recuperación de la memoria histórica". Olivar, vol. 16, 24. 2015.

http://www.olivar.fahce.unlp.edu.ar/article/view/Olivar2015v16n24a02

\footnotetext{
$(\mathrm{cc}) \mathbf{E Y} \quad$ New articles in this journal are licensed under a Creative Commons Attribution 4.0 United States License.

ULLS D-Serle This site is published by the University Library System, University of Pittsburgh as part of its D-Scribe Digital Publishing Program and is cosponsored by the University of Pittsburgh Press.
} 